\title{
Introduction to Special Section of Journal of Religion and Health, 'Mental Health, The Mind and Consciousness: Tibetan and Western Approaches'
}

\author{
Geoffrey Samuel $^{1,2} \cdot$ Susannah Deane ${ }^{3}$
}

Published online: 20 March 2019

(c) Springer Science+Business Media, LLC, part of Springer Nature 2019

This special section of the Journal of Religion and Health derives from a workshop held in July 2017 at the Centro Incontri Umani, Ascona, Switzerland. Ascona is by the side of Lago Maggiore, close to the Italian border, and the Centro is set in a beautiful garden overlooking the lake (Fig. 1). It is a small private anthropological research centre which was set up some years ago by Angela Hobart in her family home in Ascona, Switzerland, in memory of her parents. It hosts visiting scholars, and holds conferences, workshops, and other activities.

This workshop was organised jointly by the Centro Incontri Umani and by Geoffrey Samuel and Susannah Deane of the Body, Health and Religion (BAHAR) Research Group, Cardiff University. Deane had recently completed her Ph.D. at Cardiff University under Samuel's supervision, and we wanted to explore some of the wider implications of Deane's and Samuel's work on Tibetan psychiatry in an open and cross-disciplinary context where we had the opportunity for extended discussion and genuine dialogue. We were very fortunate in our group of participants, not all of whom are represented in this special section, but all of whom contributed to the ongoing discussion. In addition to those who are included in this collection, Sonu Shamdasani and Güzin Yener also presented papers, while Maggie Baron, Betina Hermes, Angela Hobart, Maya Hobart, David Nugent, Santi Rozario, and TsungHan Tsai attended some or all of the sessions. We particularly wish to acknowledge the support of Angela Hobart, director of the Centro, who both hosted the workshop and participated deeply and generously in our discussions.

The articles, which were written and developed in dialogue, cover a series of mutually related topics. They highlight the differences between Tibetan and Western approaches to both mental (or psychiatric) illness and mental health, but also ways in which they might illuminate each other, leading perhaps to a more

Geoffrey Samuel

SamuelG@ cardiff.ac.uk

1 School of History, Archaeology and Religion, Cardiff University, Cardiff, UK

2 School of Languages and Cultures, University of Sydney, Sydney, Australia

3 Department of Religion and Theology, University of Bristol, Bristol, UK 


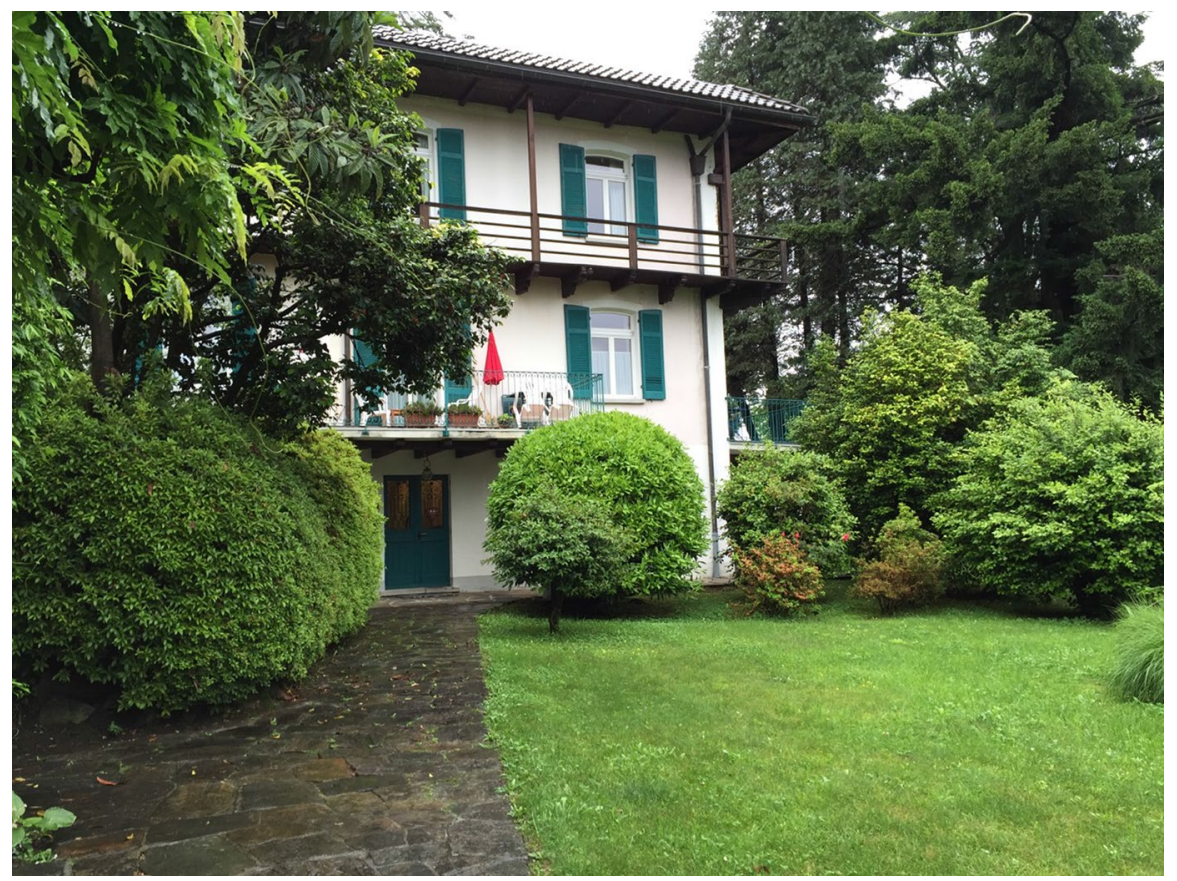

Fig. 1 Centro Incontri Umani, Ascona. Photograph by Geoffrey Samuel

effective therapeutic practice. The argument in these articles moves between levels and disciplines, encompassing methodological issues, ethnography, Tibetan studies, meditation, psychotherapy, and neuroscience. We hope that the connections and resonances between the various papers will prove stimulating and illuminating to readers from many different backgrounds.

The first article, by Ruth Smith, narrates her personal experience of contemporary Western mental health care. This encompasses both 'orthodox' psychiatry and some of the alternative approaches that have developed in recent years. Smith's daughter was diagnosed with psychiatric illness in 2005, leading to an extended encounter over the following years with psychiatric care as delivered by the U.K. National Health Service in two British cities. Her narrative is not always easy reading, but it throws into stark relief much of what can and often does go wrong in orthodox psychiatric care in contemporary Western societies. A particular issue here is the high level of usage of antipsychotic medication. Over time, Smith learned to understand, and at times contest, the treatment her daughter was receiving, and to discover what alternative resources might be available. She is now a lay member of a project at Kings College London investigating the reduction of antipsychotic medication in psychiatric treatment. This opening article confronts us with the reality of most Western psychiatric care today, but also points to other approaches. Can a sustained look at another approach to mental health be of assistance in developing alternatives? 
Susannah Deane's paper, which follows, moves us halfway across the planet, to the Tibetan population of the hill-town Darjeeling in Northeast India, and introduces a very different regime of psychiatric treatment, that of Tibetan medicine. Deane focusses in particular on the concept of rlung (pronounced 'loong'), often translated as 'wind' and referring to an internal flow or psychogenic factor within the human body and mind. Various mental disorders are understood both by lay Tibetans and by practitioners of traditional Tibetan medicine as associated with disturbances in these internal flows, and treatment involves a variety of therapies, including herbal medicines, physical therapies such as massage and moxibustion, as well as emotional support and appropriate diet. Deane, whose book on her Darjeeling research, Tibetan Medicine, Buddhism and Psychiatry, recently appeared (Deane 2018), gives a general description and analysis of this system of healing, and discusses some of the differences between Western and Tibetan approaches.

Francis Tiso's article, which follows, is also on Tibet, but rather than looking at mental imbalance and illness, it examines the ultimate aim of Tibetan religious life as defined by one major strand of Tibetan Buddhism, dzogchen. Tiso's article brings up an important theme for these studies as a whole. Western psychiatry essentially treats mental illness, as a deviation from a relatively unproblematic and unquestioned state of good health. For traditional Tibet, however, as for Ayurveda in India (Alter 1999), illness implies not so much a deviation from 'normal good health' as an obscuration or limitation of an ultimately unbounded ideal state or condition. For the Tibetans this unbounded state is Buddhahood, and this is in a sense the ultimate goal of any process of healing.

Tiso begins with a series of methodological issues. How do we move past the stereotypical and sterile opposition of 'science' and 'religion'? Tiso suggests that anthropology can aid in bringing about a 'new approach to "religious consciousness" as it is lived in real human communities'. His own investigations focussed on one of the most exotic of Tibetan religious claims, the ability of advanced yogic practitioners to dissolve their physical bodies into the elements, achieving so-called rainbow body at death. This is held to be a rare achievement, but a number of people are said to have attained the rainbow body in recent times, and Tiso undertook fieldwork on one recent occurrence, in 1998. His account, in part a reflection on his recent book, Rainbow Body and Resurrection (Tiso 2016) points to the complexities of achieving a measure of genuine communication across cultural boundaries. 'We are always translating; we are always describing an observed set of phenomena to a community of discourse that for various reasons understands reality in ways that are distinct from the ways by which another particular society understands reality. The task of the scholar is to translate without "betrayal". in terms that are faithful to the data gathered in the act of observation'.

Maria Kozhevnikov's article, which follows, takes a different approach to Tibetan spiritual practice, seeing it in terms of achieving higher levels of human performance, and specifically of enhancing human cognition. This reflects the claims of yogic practitioners in the Tibetan Vajrayāna tradition to achieve high levels of insight into the processes of human consciousness. Buddhahood, in the Buddhist conception, is centrally a process of awakening (bodhi). While that awakening has a strong ethical dimension, and is grounded in the motivation to relieve the sufferings 
of others, it can also be studied in neuroscientific terms, as a 'retuning' of the patterns of operation of the human body and nervous system. Kozhevnikov's systematic research on meditators in Tibetan and other Buddhist meditative systems has opened up new avenues in neuroscientific research, and this article gives a clear and accessible account of her research findings. Her work links up with Mihaly Csikszentmihalyi's well-known writings on 'flow' (e.g. Csikszentmihalyi 2014), but provides an account more solidly grounded in neuroscience and human cognition than Csikszentmihalyi was able to achieve.

Judith Pickering's paper returns us to mental illness. In traditional Indian philosophy, Buddhism was the teaching that denied the existence of the self as a solid and continuing entity. Exactly what this means, and how it can be understood, occupied some of the greatest minds of Asia, from Nāgārjuna onwards, over many centuries. Buddhist concepts of non-self are particularly difficult to relate to Western models of the self, with their very different philosophical and religious background. It is hardly surprising that they can become a trap for Westerners lost in existential loneliness, and whose own sense of self is weakly constituted. Pickering's approach to such problems is founded in psychoanalytic thought and also in her own therapeutic practice. She uses the language of psychoanalysis to help clarify how the Buddhist 'denial' of self can be seen in other terms. Here she is particularly interested in relational psychoanalytic approaches such as those of Fairbairn, Winnicott, and Bion, as well as in philosophers such as Buber, Merleau-Ponty, and Lévinas. For Pickering, self-realisation-individuation in Jungian terms-implies both other-realisation, and the transcendence of the dualism of self and other. 'Responsiveness to the primordial call of others, valuing their unfathomable alterity with a concomitant outflowing of care and compassion, may serve to enable liberation from the confines of a narrow and rigid self-centrism'. As Lévinas might put it, 'we become substantial through being subject to the ethical call of the other for our solicitude and care'. Pickering's article gives a sense of how a spiritually informed psychotherapy might work, a theme which is developed further in her recent book, The Search for Meaning in Psychotherapy (Pickering 2019).

Geoffrey Samuel's closing article does not attempt to order the variety of complex and subtle perspectives opened up in these various studies into a tidy picture. In returning, however, to the question of rlung within both Tibetan conceptions of mental illness, and Tibetan concepts of ultimate health, it shows some of the connections between the fields of psychiatric illness and health, both within Tibetan thought and within Western science. Perhaps learning to control the currents of rlung can be seen as a way of learning to grasp and operate with the human nervous system, a possibility towards which Kozhevnikov's work also points. Samuel points to how Tibetan understandings of mental illness in terms of unbalanced flows of rlung resemble Western understandings of mental illness in terms of malfunctioning of the nervous system. The Tibetan model of the interplay of consciousness and rlung provide a model that goes beyond reductive materialism but avoids the simplistic and unproductive dualism of mind and matter. New and more sophisticated approaches to the relationship between neuroscience and human functioning, such as Porges's polyvagal model or the predictive processing models developed by Friston and others, may offer greater possibilities for convergence and mutual 
understanding. Tibetan approaches to mental health have their own value, grounded in a very different understanding of the world to that of most modern biomedicine and psychiatry. Bridge-building of this kind could be a vital and necessary step towards a real integration of the resources and approaches of these apparently so different traditions of healing. Ultimately, our goal should surely be to appreciate the full depth and value of each, so that both can contribute to a therapeutically richer and more effective healing practice.

\section{References}

Alter, J. S. (1999). Heaps of health, metaphysical fitness: Ayurveda and the ontology of good health in medical anthropology. Current Anthropology, 40(Supplement), S43-S66.

Csikszentmihalyi, M. (2014). Flow and the foundations of positive psychology: The collected works of Mihaly Csikszentmihalyi. Dordrecht: Springer.

Deane, S. (2018). Tibetan medicine, buddhism and psychiatry: Mental health and healing in a Tibetan exile community. Durham, NC: Carolina Academic Press.

Pickering, J. (2019). The search for meaning in psychotherapy: Spiritual practice, the apophatic way, and bion. London and New York: Routledge.

Tiso, F. V. (2016). Rainbow body and resurrection: Spiritual attainment, the dissolution of the material body, and the case of Khenpo A Chö. Berkeley, CA: North Atlantic Books.

Publisher's Note Springer Nature remains neutral with regard to jurisdictional claims in published maps and institutional affiliations. 